Supplement of

\title{
Simulation of SOA formation from the photooxidation of monoalkylbenzenes in the presence of aqueous aerosols containing electrolytes under various $\mathrm{NO}_{x}$ levels
}

Chufan Zhou et al.

Correspondence to: Myoseon Jang (mjang@ufl.edu)

The copyright of individual parts of the supplement might differ from the CC BY 4.0 License. 


\section{Section S1. Measurement of aerosol acidity using the C-RUV technique}

In the presence of organic matter $(\mathrm{OM})$, the aerosol acidity (proton concentration: $\left[\mathrm{H}^{+}\right]$, mol $\mathrm{L}^{-1}$ of aerosol) reduction in aerosols could be considered by two forces: (1) the neutralization with atmospheric ammonia and (2) the formation of alkyl substituted sulfates, which includes monoalkyl sulfates and dialkyl sulfates (diOS). Due to the strong acidity of monoalkyl sulfates, we only attributed the reductions in aerosol acidity and hygroscopicity to the formation of diOS. Using the inorganic concentrations measured by the PILS-IC, where organosulfate was reversed to sulfate ion due to high-temperatures $\left(>80^{\circ} \mathrm{C}\right)$ water vapor, the proton concentration, which results only from ammonia neutralization, can be predicted through the inorganic thermodynamic model EAIM-II (Clegg and Seinfeld, 2006). The proton concentration, which was associated with both ammonia neutralization and diOS formation, was measured by colorimetry integrated with the reflectance UV-visible spectrometer (CRUV) technique (Jang et al., 2008; Li et al., 2016;Li and Jang, 2012), which utilized a UVvisible spectrometer in absorbance mode to detect the color change on a sample-collected dyed filter. Thus, the difference between the two measured $\left[\mathrm{H}^{+}\right]$values is due to the formation of diOS. The reduction in sulfate concentration, which equalizes the PILS-IC measured $\left[\mathrm{H}^{+}\right]$to the C-RUV measured $\left[\mathrm{H}^{+}\right]$, is the measured diOS concentration ([diOS $]_{\text {exp }}$ ). The C-RUV method has been previously applied to toluene and 1,3,5-trimethylbenzene SOAs (Im et al. (2014) and isoprene SOA (Beardsley and Jang (2016). 


\section{Section S2. Lumping structure}

The oxygenated products are lumped into $n$ bins $(n=8)$ based on their volatility (mmHg): $10^{-8}, 10^{-6}, 10^{-5}, 10^{-4}, 10^{-3}, 10^{-2}, 10^{-1}$, and 1 . The vapor pressure of the products was estimated by a group contribution method (Stein and Brown, 1994;Zhao et al., 1999), which has been applied by the development of the UNIPAR model (Im et al., 2014;Beardsley and Jang, 2016). Each volatility group was further classified into $m$ bins $(m=8)$ based on the aerosolphase chemical reactivity: very fast (VF), fast (F), medium (M), slow (S), partitioning only (P), and multi-alcohol (MA), as shown in a previous paper (Beardsley and Jang, 2016). GLY, MGLY, and isoprene products only (IEPOX) are separately treated in UNIPAR and represented as Reactive (R) group because of their significant contributions to SOA formation (Jang and Kamens, 2001;Jang et al., 2002). The detailed products distributions were shown in the Tables S1-S3.

The mass-based stoichiometric coefficient $\left(\alpha_{i}\right)$ of species, $i$, was constructed, as shown in Eq. S1, to calculate the gas-phase concentration $\left(\mu \mathrm{g} \mathrm{m}^{-3}\right.$ of air) of each lumping species, $i$.

$$
\begin{aligned}
& \text { HCs }+ \text { oxidants } \rightarrow \alpha_{1} S_{1}+\alpha_{2} S_{2}+\cdots+\alpha_{8} S_{8} \\
& +\alpha_{9} S_{9}+\alpha_{10} S_{10}+\cdots+\alpha_{16} S_{16}
\end{aligned}
$$

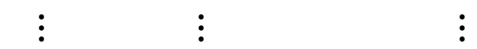

$$
\begin{aligned}
& +\alpha_{41} S_{41}+\alpha_{42} S_{42}+\cdots+\alpha_{48} S_{48} \\
& +\alpha_{49} S_{49}+\alpha_{50} S_{50}+\alpha_{51} S_{51} \\
& =\sum_{i=1 \sim 51} \alpha_{i} S_{i} \text {, }
\end{aligned}
$$

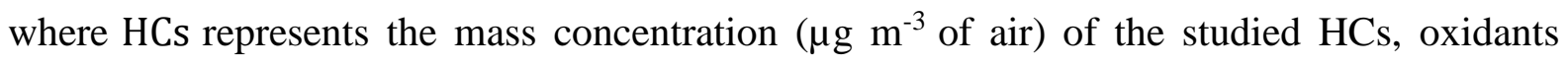
represent the atmospheric oxidants (e.g., $\mathrm{OH}$ radical, $\mathrm{O}_{3}$, and $\mathrm{NO}_{3}$ ), $\alpha_{i}$ represents the massbase stoichiometric coefficient of species $i$, and $S_{i}$ represents lumped species $i$. The model parameters related to thermodynamic equilibrium process and reactivity are also treated based on $\alpha_{i}$. 


\section{Section S3. Estimation of the atomic oxygen-to-carbon ratio $\left(O: C_{i}\right)$ and molecular weight $\left(M W_{i}\right)$ for each lumping species}

We assume that the model parameters (i.e., atomic oxygen-to-carbon ratio $\left(O: C_{i}\right)$, molecular weight $\left(M W_{i}\right)$, and hydrogen bonding ( $\left.H B_{i}\right)$ parameter) related to the thermodynamic equilibrium process of a lumping group (see Section S4) linearly change as a function of $\mathrm{NO}_{x}$ levels, which range from $\mathrm{HC} / \mathrm{NO}_{x}=2\left(\right.$ high $\mathrm{NO}_{x}$ level $\left.\left(\mathrm{H}-\mathrm{NO}_{x}\right)\right)$ to $\mathrm{HC} / \mathrm{NO}_{x}=14$ (the low $\mathrm{NO}_{x}$ level $\left(\mathrm{L}-\mathrm{NO}_{x}\right)$ ).

For example, the calculation of the $O: C_{i}$ is exemplified in the following part in this Section. Based on the simulations from the near-explicit gas kinetic model under the same metrological condition (6/19/2015), four sets of $O: C_{i}$ are carried out under four conditions:

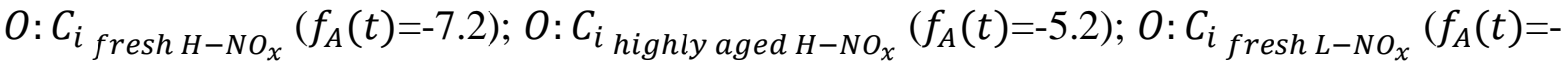
3.7); and $O: C_{i}$ highly aged $L-N O_{x}\left(f_{A}(t)=-2.9\right)$, where $f_{A}(t)$ is the aging factor at time $=t . f_{A}(t)$ is defined in Eq. 1 in the manuscript. Thus, the fresh set of $O: C_{i}\left(O: C_{i}\right.$ fresh $)$ at a given $\mathrm{NO}_{x}$ condition can be approached by the similar weighted average method (Section 3.2.2 in the manuscript) by combining the two sets of $O: C_{i}{\text { fresh } H-N O_{x}}$ and $O: C_{i_{\text {fresh L-NO}}}$, as is shown in Eq. S2. The fractional weighting scale $\left(f_{N O_{x}}{ }^{\prime}(t): 0-1\right.$ scale) is estimated by scaling the given $\mathrm{HC} / \mathrm{NO}_{x}$ within the upper boundary $\left(\mathrm{HC} / \mathrm{NO}_{x}=14\right)$ and the lower $\left(\mathrm{HC} / \mathrm{NO}_{x}=2\right)$ boundary. Similarly, the highly aged set of $O: C_{i}\left(O: C_{i}\right.$ highly aged $)$ can be obtained by combining $O: C_{i}$ highly aged $H-N O_{x}$ and $O: C_{i}$ highly aged $L-N O_{x}$ using $f_{N O_{x}}{ }^{\prime}(t)$, as shown in Eq. S3.

$$
\begin{gathered}
O: C_{i_{\text {fresh }}}=\left(1-f_{N O_{x}}(t)\right) \cdot O: C_{i_{\text {fresh } H-N O_{x}}+f_{N O_{x}}{ }^{\prime}(t) \cdot O: C_{i_{\text {fresh } L-N O}}} \\
O: C_{i_{\text {highly aged }}}=\left(1-f_{N O_{x}}{ }^{\prime}(t)\right) \cdot O: C_{i_{\text {highly aged } H-N O_{x}}}+f_{N O_{x}}{ }^{\prime}(t) \cdot O: C_{i_{\text {highly aged } L-N O_{x}}}
\end{gathered}
$$

Since the change of the $O: C_{i}$ of the lumping species, $i$, is due to the evolution of the gas-phase products, which is governed by the $\alpha_{i}$, the dynamic $O: C_{i}$ set can be simply estimated by comprising the $O: C_{i}$ fresh ${ }$ and $O: C_{i}$ highly aged using the aging scale, $f_{A}{ }^{\prime}(t)$, as shown in Eq. S4 (same method in Eq. 2 in the manuscript).

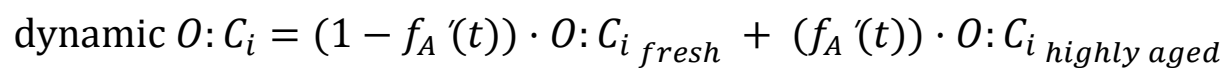

The calculation of dynamic $M W_{i}$ and dynamic $H B_{i}$ is also treated with the similar method used for the dynamic $O: C_{i}$. dynamic $O: C_{i}, M W_{i}$, and $H B_{i}$ sets are applied to estimate the activity coefficient of the organics in the inorganic (in) phase, as shown in Eq. 4 in the manuscript. 


\section{Section S4. Activity coefficient of organic species in the aqueous solutions containing electrolytes}

In the UNIAPR model, the formation of aromatic SOA is simulated with the assumption of organic-inorganic phase separation. To predict the partitioning of organic species on both the organic phase and the inorganic phase, the key model parameters are $K_{o r, i}$ and $K_{i n, i}$, respectively (described in Section 3.2 of the main manuscript). In order to predict $K_{i n, i}$, the calculation of the activity coefficient $\left(\gamma_{i n, i}\right)$ of organic species in the inorganic phase (aqueous phase containing electrolytes) is necessary.

In our study, $\gamma_{i n, i}$ was semi-empirically predicted by a polynomial equation, which was fit the theoretical $\gamma_{i n, i}$ of various organic compounds to relative humidity $(R H)$, fractional sulfate $(F S)$, and molecular structures such as atomic oxygen-to-carbon ratio $\left(O: C_{i}\right)$, molecular weight $\left(M W_{i}\right)$, and hydrogen bonding $\left(H B_{i}\right)$ parameter. The solubility of an organic compound can be increased with increasing $O: C_{i}$. A hydrogen bonding donor functionality can more significantly influence the solubility of organic compounds in aqueous phase. The $H B_{i}$ of each product is estimated by counting the number of hydrogen bonding donor functionality such as alcohol $(-\mathrm{OH})$, hydrogen peroxide $(-\mathrm{OOH})$, carboxylic acid $(-\mathrm{C}(=\mathrm{O}) \mathrm{OH})$, and peroxyacid ($\mathrm{C}(=\mathrm{O}) \mathrm{OOH})$. In general, carboxylic acid has stronger hydrogen bonding ability. Thus, carboxylic acid and peroxyacid are scaled with 1.6 for counting $H B_{i} . O: C_{i}, M W_{i}$, and $H B_{i}$ parameters for each lumping species $(i)$ are obtained by summing up the mass-weighted parameters of each product in the corresponding lumping species.

The theoretical $\gamma_{i n, i}$ was determined at the maximum solubility of organic species in the electrolytic aqueous phase $\left(\mathrm{SO}_{4}{ }^{2-}-\mathrm{NH}_{4}{ }^{+}-\mathrm{H}_{2} \mathrm{O}\right.$ system) using the Aerosol Inorganic-Organic Mixtures Functional Groups Activity Coefficients (AIOMFAC) (Zuend et al., 2011). AIOMFAC was run for the estimation of $\gamma_{i n, i}$ of 20 model compounds with diverse $M W_{i}, O: C_{i}$, and $H B_{i}$ under varying inorganic phase compositions (FS and hygroscopicity linked to $\mathrm{RH}$ ). The oligomeric products form in aqueous phase, but they deposit to the organic phase due to their poor solubility in inorganic phase. However, some hydrophilic oligomers can dissolve in both organic and inorganic phases. For example, glyoxal-origin oligomers might be hydrophilic and partially soluble in inorganic phase. Hence, the trace amount of glyoxaloligomer $(\mathrm{MW}=290 \mathrm{~g} / \mathrm{mol}$ and $\mathrm{O}: \mathrm{C}=1$ with mole fraction $=0.01)$ was included in inorganic phase as seen in Table S4. In Figure S1, the $\gamma_{i n, i}$ predicted by AIOMFAC was plotted to that predicted by the polynomial equation (Eq. 4 in the manuscript) along with the one-to-one line 
for 20 organic species (Table S4). $O: C_{i}, M W_{i}$, and $H B_{i}$ range from 0.14 to 1.2, 58.00 to 204.18, 0.0 to 3.2 , respectively. FS ranges from 0.34 to 1.0 and $\mathrm{RH}$ ranges from 0.1 to 0.8 .

Table S4: The molecular structures, O:C ratios, $\mathrm{MW}$, and HB of the oligomeric compound (a) and 20 model compounds (b), which were employed to derive the polynomial equation to predict $\gamma_{i n, i}$ of organic species in the electrolytic aqueous phase. The name of the compound with symbol * originates from MCM (http://mcm.leeds.ac.uk/MCMv3.3.1/home.htt).

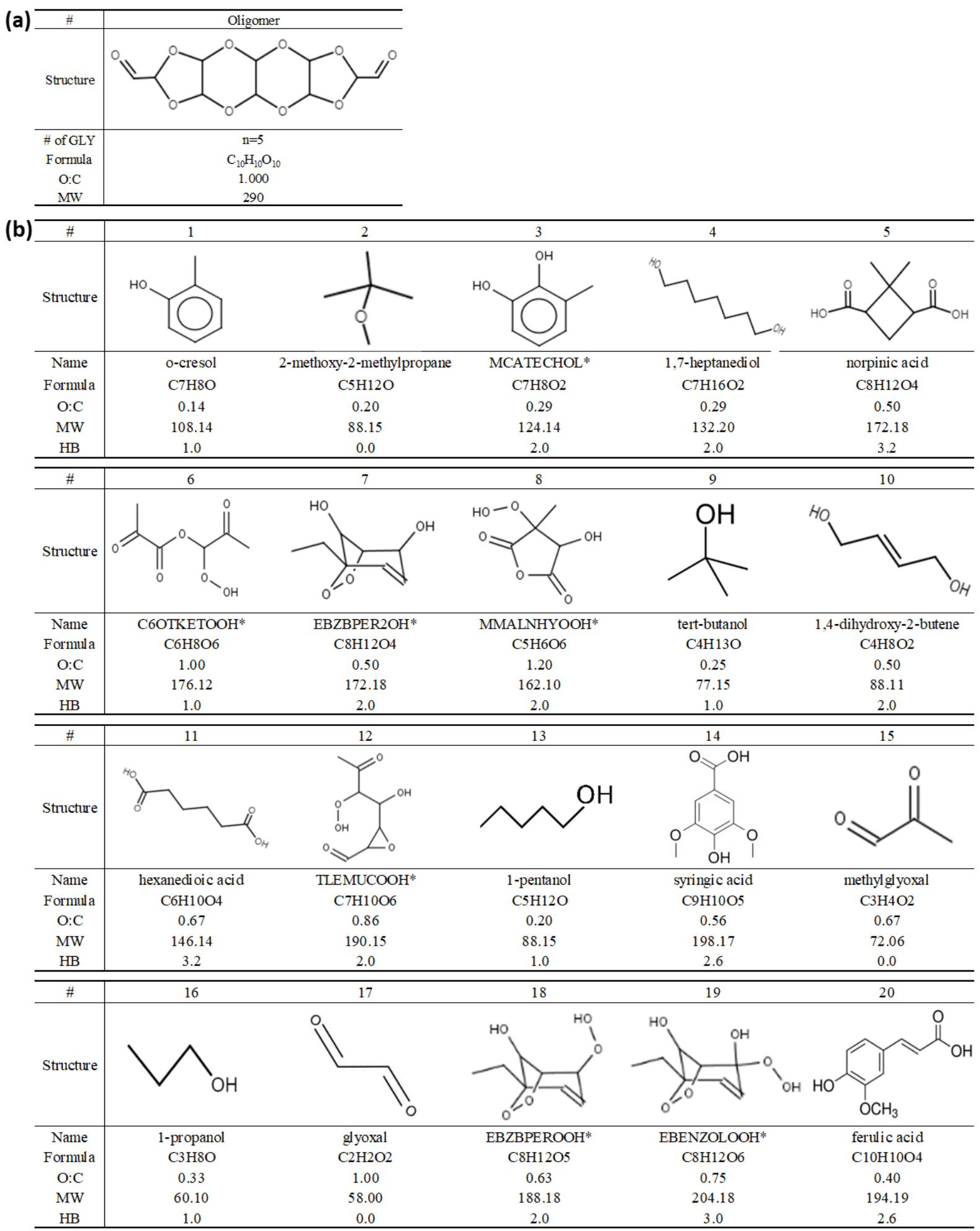




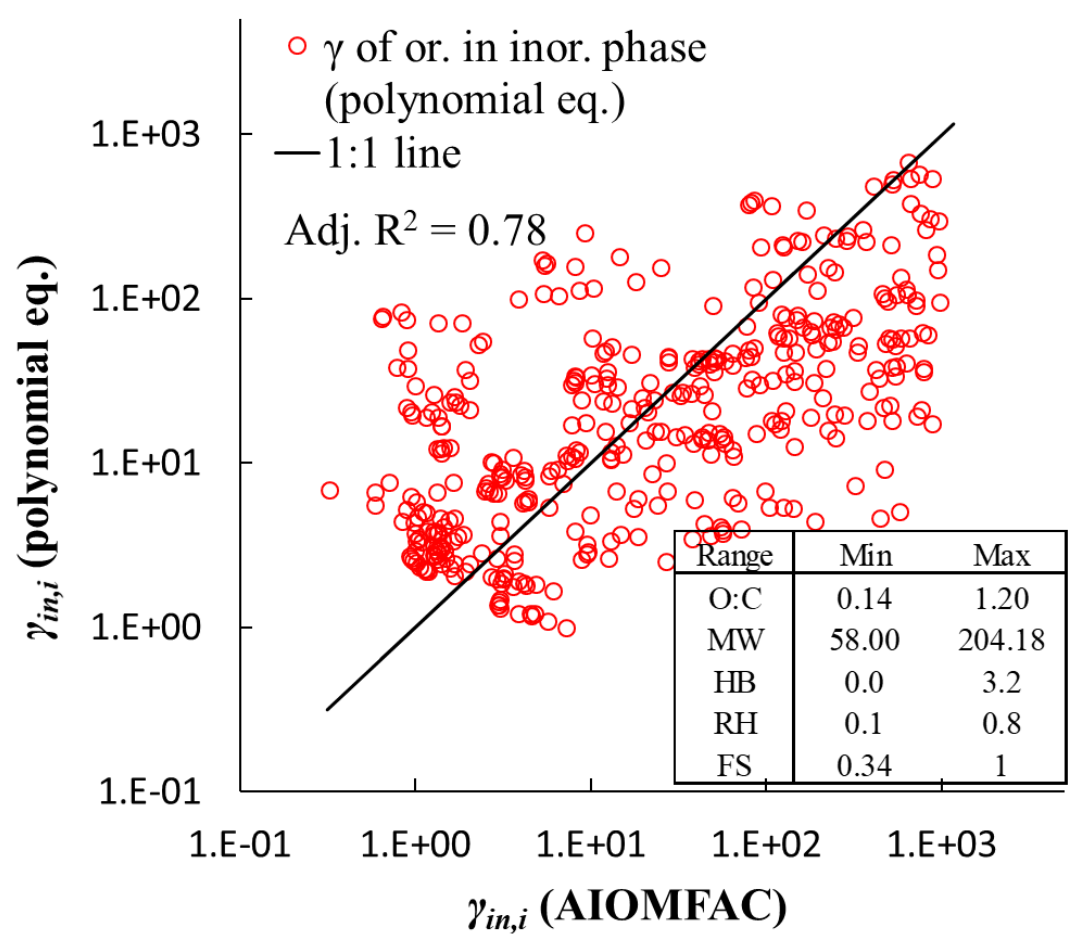

Figure S1: The $\boldsymbol{\gamma}_{\boldsymbol{i n}, \boldsymbol{i}}$ predicted by AIOMFAC was plotted to that predicted by the polynomial equation $\left(\gamma_{i n, i}=e^{0.035 \cdot M W_{i}-2.704 \cdot \ln \left(O: C_{i}\right)-1.121 \cdot H B_{i}-0.330 \cdot F S-0.022 \cdot(100 \cdot R H)}\right.$, Eq. 4 in the manuscript) along with the one to one line for model compounds in Table S4.

\section{Section S5. Derivation of the model equations used to predict the organic mass}

The gas-organic phase partitioning coefficient $\left(K_{o r, i}, \mathrm{~m}^{3} \mu \mathrm{g}^{-1}\right)$ and the gas-inorganic phase partitioning coefficient $\left(K_{i n, i}, \mathrm{~m}^{3} \mu \mathrm{g}^{-1}\right)$ of each species are obtained from Eq. 3 in the manuscript. The concentrations $\left(C_{g, i}, C_{o r, i}\right.$, and $C_{i n, i}: \mu \mathrm{g} \mathrm{\textrm {m } ^ { - 3 }}$ of air) of each lumping species in the gas ( $g$ ), organic aerosol (or), and inorganic (in) phases can be derived from the Eqs. S6, S7, and S8, respectively. The partitioning and aerosol-phase reactions in the multiphase system $(g, o r$, and in phase) can be kinetically represented as shown in Fig. S2.

$$
\begin{aligned}
& C_{g, i}=\frac{C_{T, i}}{1+K_{o r, i} O M_{T}+K_{i n, i} M_{i n}} \\
& C_{o r, i}=\frac{C_{T, i} K_{o r, i} O M_{T}}{1+K_{o r, i} O M_{T}+K_{i n, i} M_{i n}} \\
& C_{i n, i}=\frac{C_{T, i} K_{i n, i} M_{i n}}{1+K_{o r, i} O M_{T}+K_{i n, i} M_{i n}},
\end{aligned}
$$

where the subscript $i$ represents the lumping species, $i . C_{T, i}$ is the total organics concentration in multiple phases (i.e., $\left.C_{T, i}=C_{g, i}+C_{o r, i}+C_{i n, i}\right) . O M_{T}$ and $M_{i n}$ are the mass 
concentration $\left(\mu \mathrm{g} \mathrm{m}^{-3}\right.$ of air) of the total organic matter and the total inorganic aerosol, respectively.

The formation of organic matter $\left(\triangle O M_{A R}\right)$ through aerosol-phase reactions are described by two processes: (1) the oligomerization in or phase and (2) the oligomerization in in phase (i.e., acid-catalyzed reaction). The two reactions are described based on the secondorder kinetic self-dimerization as shown in Eqs. S9 and S10.

$$
\begin{aligned}
& \frac{d C_{o r, i}}{d t}=-k_{o, i} C_{o r, i}^{\prime}{ }^{2}\left(\frac{M W_{i} O M_{T}}{\rho_{o r} 10^{3}}\right) \\
& \frac{d C_{i n, i}}{d t}=-k_{A C, i} C_{i n, i}^{\prime}{ }^{2}\left(\frac{M W_{i} M_{i n}}{\rho_{\text {in }} 10^{3}}\right),
\end{aligned}
$$

where $C_{o r, i}^{\prime}$ and $C_{i n, i}^{\prime}$ are the aerosol-base organic concentration $\left(\mathrm{mol} \mathrm{L}^{-1}\right)$ in in phase and or phase, respectively. $k_{o, i}$ and $k_{A C, i}$ are the second order reaction rate constant $\left(\mathrm{L} \mathrm{mol}^{-1} \mathrm{~s}^{-1}\right)$ for oligomerization in the or phase and the in phase, respectively. The conversion of the aerosolbase concentration $\left(C_{o r, i}^{\prime}\right.$ and $\left.C_{i n, i}^{\prime}\right)\left(\mathrm{mol} \mathrm{L}^{-1}\right)$ to air-base concentration $\left(C_{o r, i}\right.$ and $\left.C_{i n, i}\right)\left(\mu \mathrm{g} \mathrm{m}^{-3}\right)$ is fulfilled by the bracketed terms, $\frac{M W_{i} O M_{T}}{\rho_{\text {or }} 10^{3}}$ and $\frac{M W_{i} M_{\text {in }}}{\rho_{\text {in }} 10^{3}}$, respectively. $\mathrm{MW}_{i}$ is the molecular weight of species, $i . \mathrm{OM}_{\mathrm{T}}$ is the total organic matter $(\mathrm{OM})$ concentration $\left(\mu \mathrm{g} \mathrm{m}^{-3}\right) . \rho_{\text {or }}$ and $\rho_{\text {in }}$ are the densities $\left(\mathrm{g} \mathrm{cm}^{-3}\right)$ of the or phase aerosol and in phase aerosol.

Based on the mass balance, $\triangle O M_{A R}$ is same as the consumed total concentrations of lumping species (sum up of $C_{T, i}$ i of each lumping species, $i$ ) as shown in the following equation.

$$
\Delta O M_{A R}=-\sum_{i} \Delta C_{T, i}=-\sum_{i} \int d C_{T, i}
$$

Thus, the following equations can be applied to kinetically express partitioning and in-particle chemistry processes of the lumping species.

$$
\begin{gathered}
\frac{d C_{g, i}}{d t}=k_{11} C_{o r, i}-k_{12} C_{g, i}+k_{21} C_{i n, i}-k_{22} C_{g, i} \\
\frac{d C_{o r, i}}{d t}=-k_{11} C_{o r, i}+k_{12} C_{g, i}-k_{31} C_{o r, i}+k_{32} C_{i n, i}-k_{o, i} C_{o r, i}^{\prime}{ }^{2}\left(\frac{M W_{i} O M_{T}}{\rho_{o r} 10^{3}}\right) \\
\frac{d C_{i n, i}}{d t}=-k_{21} C_{i n, i}+k_{22} C_{i n, i}+k_{31} C_{o r, i}-k_{32} C_{i n, i}-k_{A C, i} C_{i n, i}^{\prime}{ }^{2}\left(\frac{M W_{i} M_{i n}}{\rho_{i n} 10^{3}}\right),
\end{gathered}
$$

where $k_{n m}$ is the first-order reaction rate constants $\left(\mathrm{S}^{-1}\right)(n=1,2,3 ; m=1,2)$ in which each couple of them denotes the equilibrium among $C_{g, i}, C_{o r, i}$ and $C_{i n, i}$ as shown in Fig. S2.

From Eqs. S12-S14, $\frac{d C_{T, i}}{d t}$ can be rewritten as following,

$$
\frac{d C_{T, i}}{d t}=\frac{d C_{g, i}}{d t}+\frac{d C_{o r, i}}{d t}+\frac{d C_{i n, i}}{d t}=-k_{o, i} C_{o r, i}^{\prime}{ }^{2}\left(\frac{M W_{i} O M_{T}}{\rho_{o r} 10^{3}}\right)-k_{A C, i} C_{i n, i}^{\prime}{ }^{2}\left(\frac{M W_{i} M_{i n}}{\rho_{\text {in }} 10^{3}}\right)
$$


Eq. S15 can be rearranged with respect to $C_{T, i}$ by plugging Eqs. S7 and S8 as following.

$$
\frac{d C_{T, i}}{d t}=\left(k_{o, i} \frac{\rho_{o r} 10^{3} O M_{T} K_{o r, i}^{2}}{M W_{i}\left(1+K_{o r, i} O M_{T}+K_{i n, i} M_{i n}\right)^{2}}+k_{A C, i} \frac{\rho_{i n} 10^{3} M_{i n} K_{i n, i}^{2}}{M W_{i}\left(1+K_{o r, i} O M_{T}+K_{i n, i} M_{i n}\right)^{2}}\right) C_{T, i}^{2}
$$

Based on the assumption that $O M_{T}, M_{i n}, k_{o, i}$, and $k_{A C, i}$ are constants during each computational time step, Eq. S16 can be solved as following by being integrated as a second-order differential equation.

$$
\Delta O M_{A R}=-\sum_{i} \Delta C_{T, i}=-\sum_{i} \int_{0}^{\Delta t}\left(k_{o, i} \beta_{1, i}+k_{A C, i} \beta_{2, i}\right) C_{T, i}^{2},
$$

where $\beta_{1, i}=\frac{\rho_{o r} 10^{3} O M_{T} K_{o r, i}^{2}}{M W_{i}\left(1+K_{o r, i} O M_{T}+K_{i n, i} M_{i n}\right)^{2}}$ and $\beta_{2, i}=\frac{\rho_{i n} 10^{3} M_{i n} K_{i n, i}^{2}}{M W_{i}\left(1+K_{o r, i} O M_{T}+K_{i n, i} M_{i n}\right)^{2}}$ are the simplified terms associating with oligomerization in the or phase and the in phase, respectively. Hence, the analytical solution corresponding to $\triangle O M_{A R}$ can be achieved as shown in the following equation.

$$
\Delta O M_{A R}=-\sum_{i} \Delta C_{T, i}=-\sum_{i} \frac{C_{T, i}^{2} \Delta t\left(k_{o, i} \beta_{1, i}+k_{A C, i} \beta_{2, i}\right)}{C_{T, i} \Delta t\left(k_{o, i} \beta_{1, i}+k_{A C, i} \beta_{2, i}\right)+1}
$$

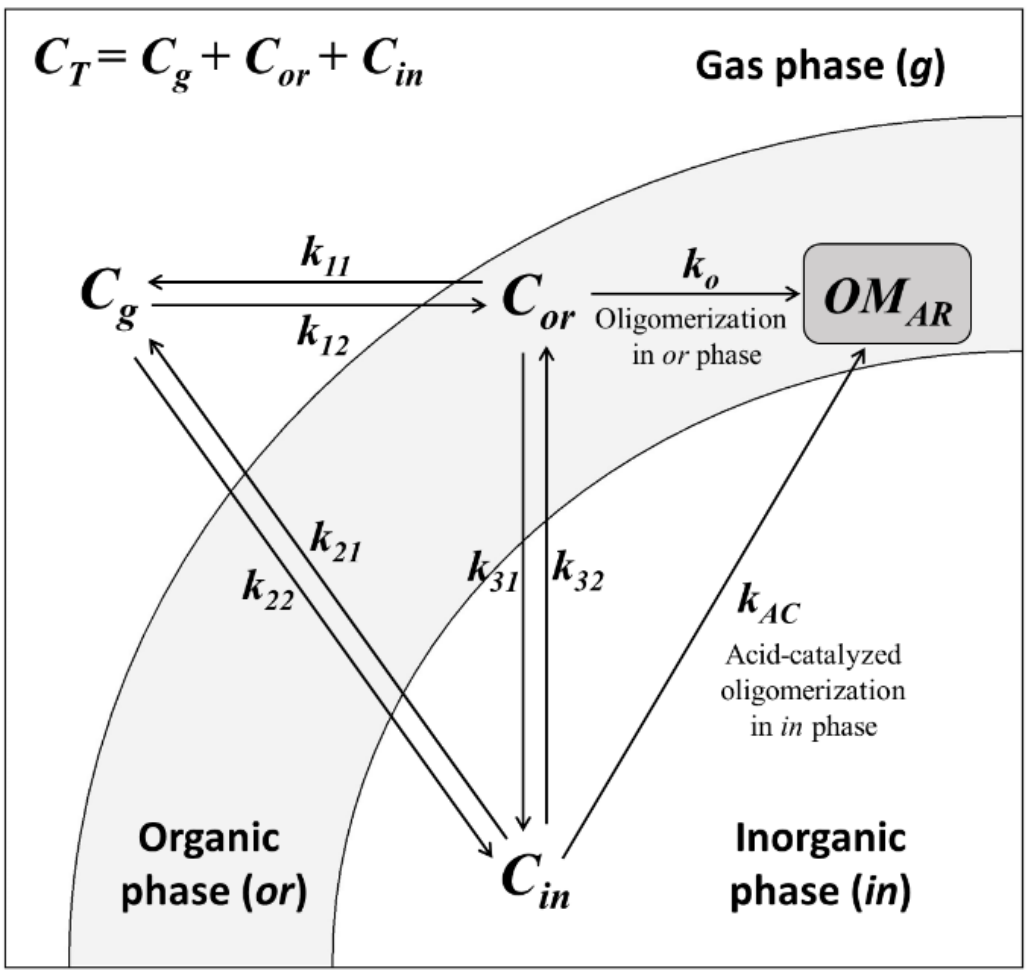

Figure S2. Simplified kinetic scheme for Fig. 1 in the manuscript for the products partitioning and aerosol-phase oligomerization in the UNIPAR model. 
Section S6. Simulation of aromatic hydrocarbons and chamber measurements

(a) Exp. Tol7, $\mathrm{HC} / \mathrm{NO}_{x}=6.4(02 / 25 / 18)$

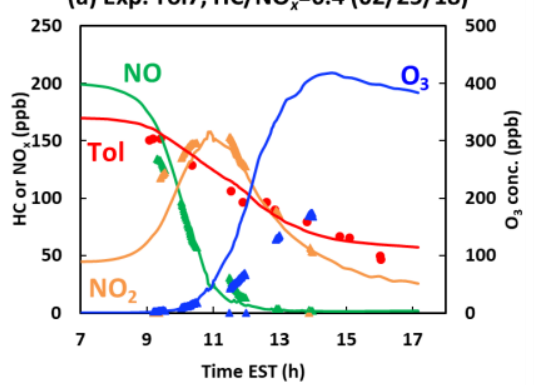

(b) Exp. EB2, $\mathrm{HC} / \mathrm{NO}_{x}=14.4(12 / 05 / 17)$

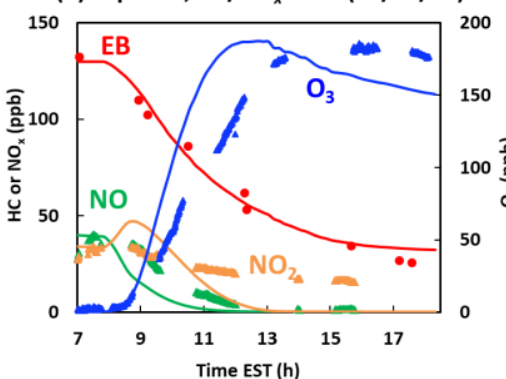

(c) Exp. PB2, $\mathrm{HC} / \mathrm{NO}_{x}=9.1(03 / 04 / 18)$

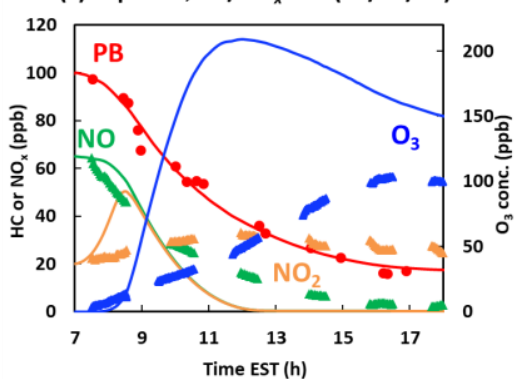

Figure S3: Time profiles of experimental measurements and simulation for three different hydrocarbons (HC): (a) toluene (Tol), (b) ethylbenzene (EB), and (c) n-propylbenzene (PB), along with $\mathrm{O}_{3}, \mathrm{NO}_{2}$, and $\mathrm{NO}$ concentration. The experimental conditions are available in Table 1 . 
Section S7. Structure of lumping species and mass-based stoichiometric coefficients

Table S1: Major oxygenated products distribution in gas phase for toluene oxidation under four conditions (i.e., high $\mathrm{NO}_{x}$ fresh, low $\mathrm{NO}_{x}$ fresh, high $\mathrm{NO}_{x}$ aged, and low $\mathrm{NO}_{x}$ aged). High $\mathrm{NO}_{x}: \mathrm{HC} / \mathrm{NO}_{x}=2$; low $\mathrm{NO}_{x}: \mathrm{HC} / \mathrm{NO}_{x}=14$.

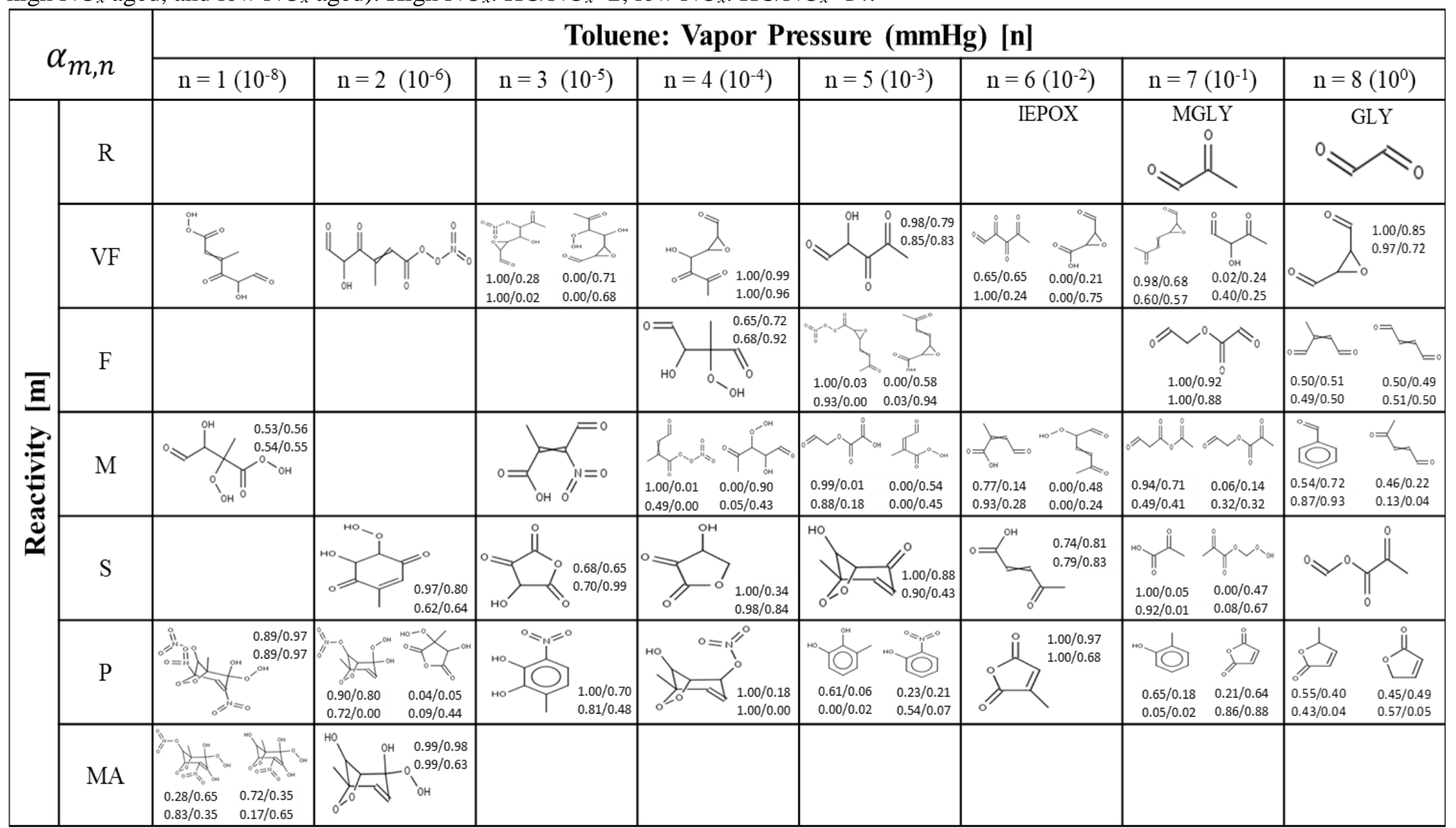

The number in the cells denotes the mass fraction of the product to the lumping species under conditions of high $\mathrm{NO}_{x}$ fresh, low $\mathrm{NO}_{x}$ fresh, high $\mathrm{NO}_{x}$ aged, and low $\mathrm{NO}_{x}$ aged, respectively (from left to right, top to bottom). No number indicates the organic compound is the major contributor (mass fraction >0.9) regardless of the $\mathrm{NO}_{x}$ condition. Some of the trivial products were not listed. 
Table S2: Major oxygenated products distribution in gas phase for ethylbenzene oxidation under four conditions (i.e., high $\mathrm{NO}_{x}$ fresh, low $\mathrm{NO}_{x}$

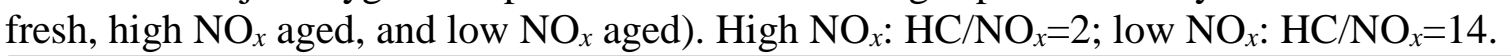

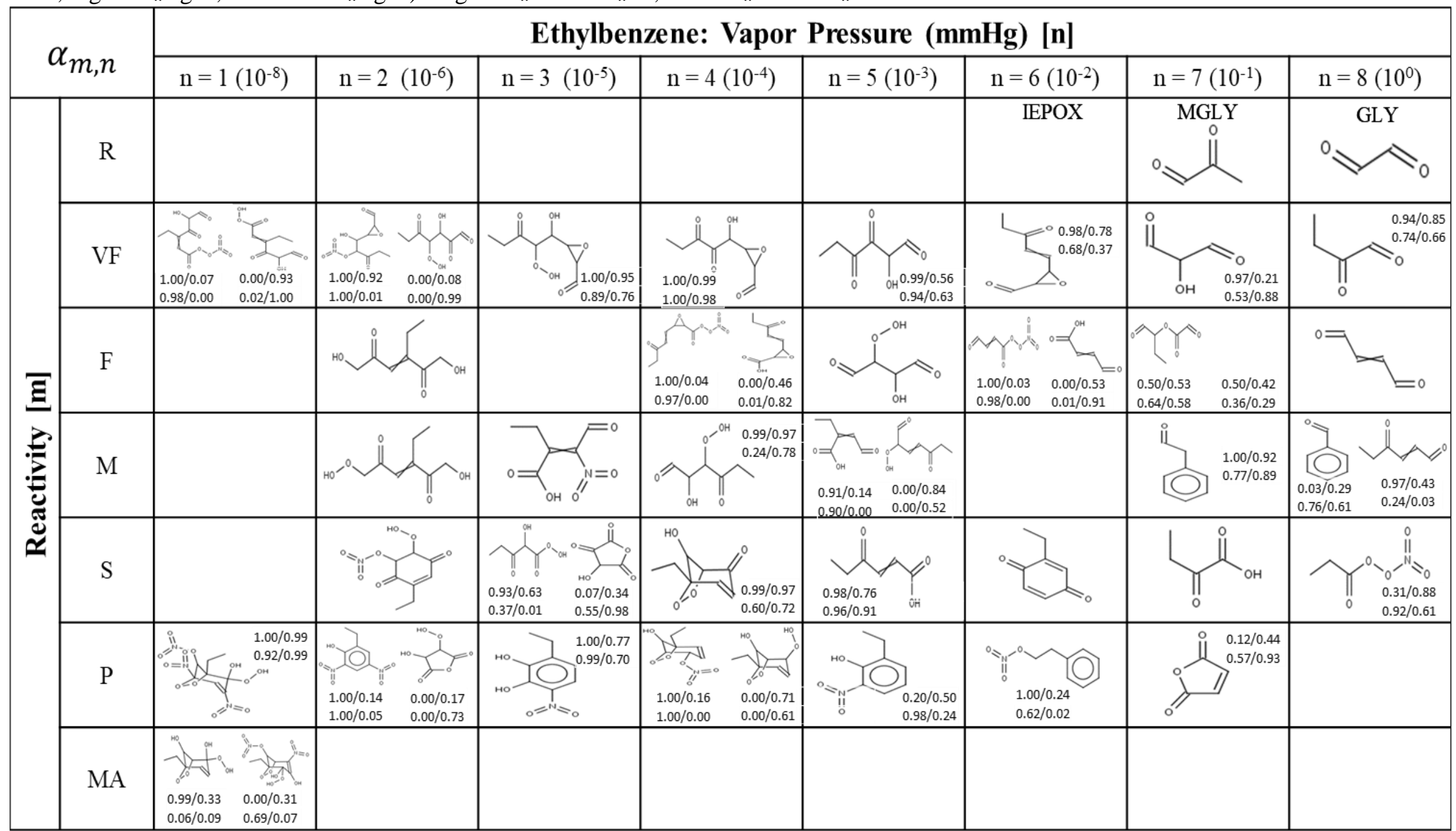

The number in the cells denotes the mass fraction of the product to the lumping species under conditions of high $\mathrm{NO}_{x}$ fresh, low $\mathrm{NO}_{x}$ fresh, high $\mathrm{NO}_{x}$ aged, and low $\mathrm{NO}_{x}$ aged, respectively (from left to right, top to bottom). No number indicates the organic compound is the major contributor (mass fraction >0.9) regardless of the $\mathrm{NO}_{x}$ condition. Some of the trivial products were not listed. 
Table S3: Major oxygenated products ocim in gas phase for n-propylbenzene under four conditions (i.e., high $\mathrm{NO}_{x}$ fresh, low $\mathrm{NO}_{x}$ fresh, high $\mathrm{NO}_{x}$ aged, and low $\mathrm{NO}_{x}$ aged). High $\mathrm{NO}_{x}: \mathrm{HC} \mathrm{NO}_{x}=2$; low $\mathrm{NO}_{x}: \mathrm{HC} / \mathrm{NO}_{x}=14$.

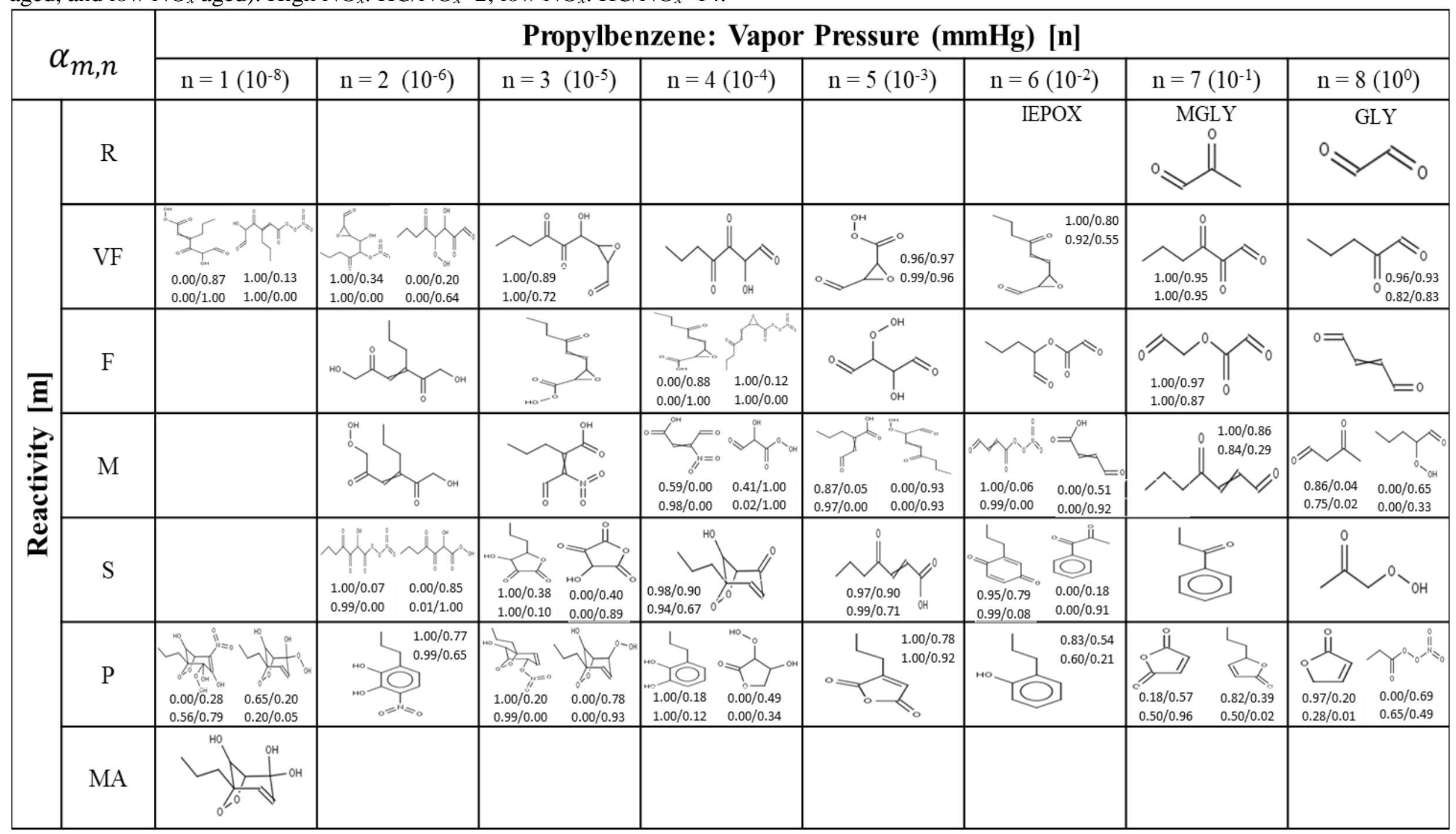

The number in the cells denotes the mass fraction of the product to the lumping species under conditions of high $\mathrm{NO}_{x}$ fresh, low $\mathrm{NO}_{x}$ fresh, high $\mathrm{NO}_{x}$ aged, and low $\mathrm{NO}_{x}$ aged, respectively (from left to right, top to bottom). No number indicates the organic compound is the major contributor (mass fraction $>0.9$ ) regardless of the $\mathrm{NO}_{x}$ condition. Some of the trivial products were not listed. 

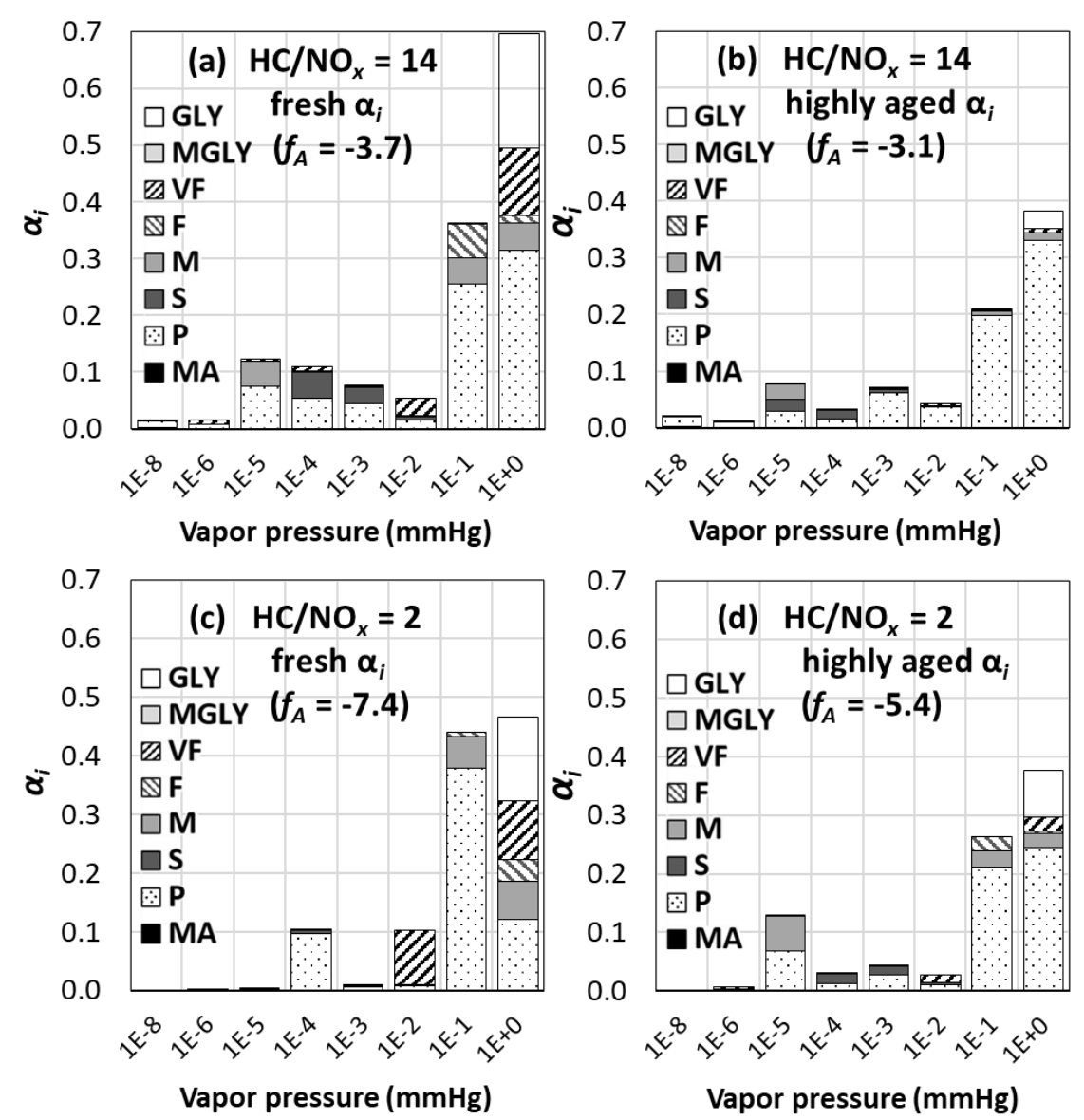

Figure S4: The mass-based stoichiometric coefficients $\left(\alpha_{i}\right)$ of each species, $i$, from ethylbenzene oxidation under low $\mathrm{NO}_{x}$ level (simulation based on the sunlight of Exp. To19, 06/14/18) at (a) fresh condition and (b) highly aged condition, and under high $\mathrm{NO}_{x}$ level at (c) fresh condition and (d) highly aged condition, where $f_{A}$ is the aging scale factor as derived in Eq. 1. The oxygenated products predicted by the explicit gas kinetic model are lumped as a function of vapor pressure (8 groups: $10^{-8}, 10^{-6}, 10^{-5}, 10^{-4}, 10^{-3}, 10^{-2}, 10^{-1}$, and $1 \mathrm{mmHg}$ ) and aerosol phase reactivity (6 groups), i.e., very fast (VF: tricarbonyls and $\alpha$-hydroxybicarbonyls), fast (F: 2 epoxides or aldehydes,), medium (M: 1 epoxide or aldehyde), slow (S: ketones), partitioning only (P), and multialcohol (MA). MGLY (methylglyoxal) and GLY (glyoxal) were lumped separately due to the relatively high reactivity. 

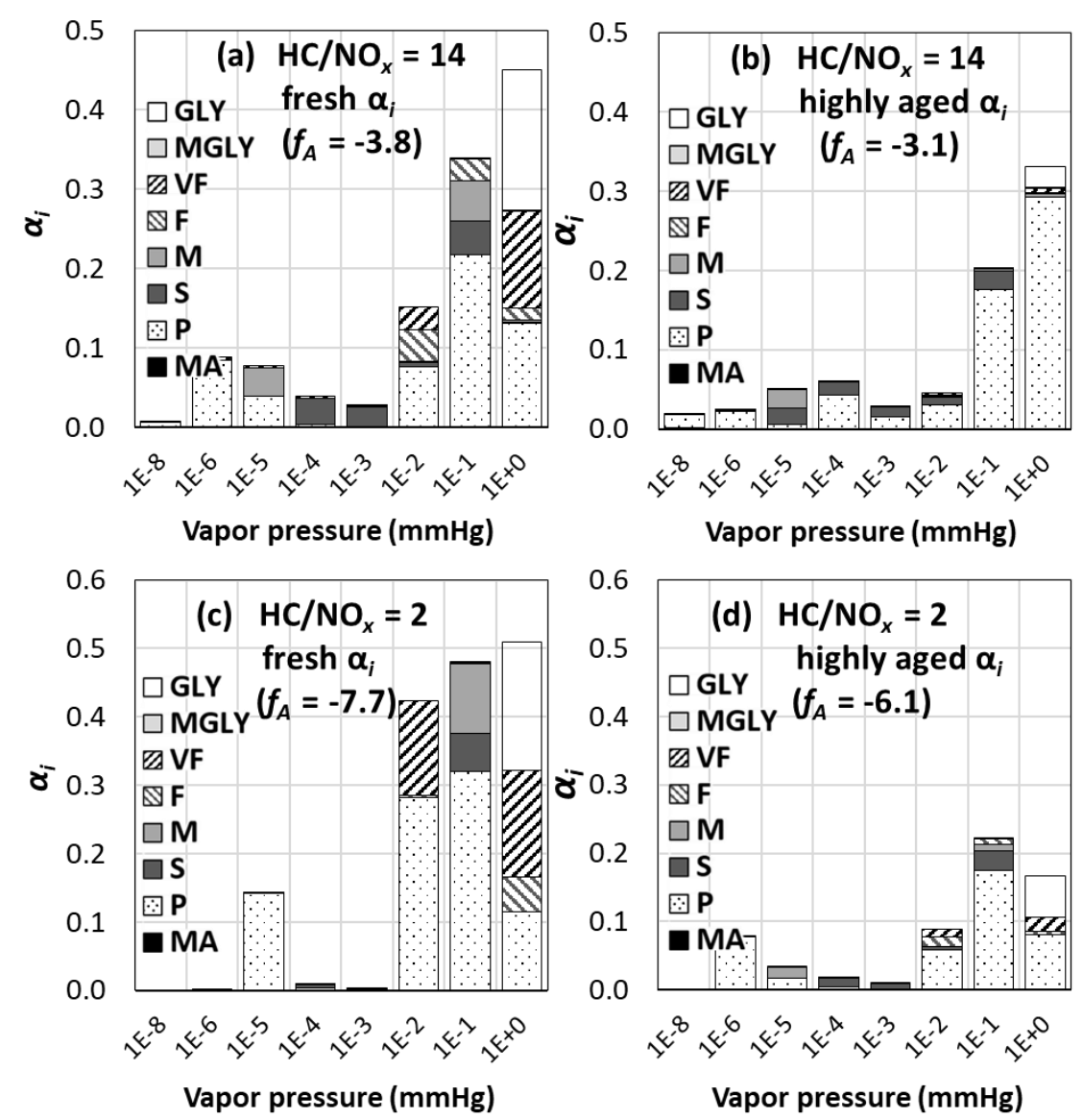

Figure S5: The mass-based stoichiometric coefficients $\left(\alpha_{i}\right)$ of each species, $i$, from npropylbenzene oxidation under low $\mathrm{NO}_{x}$ level (simulation based on the sunlight of Exp. Tol9, 06/14/18) at (a) fresh condition and (b) highly aged condition, and under high $\mathrm{NO}_{x}$ level at (c) fresh condition and (d) highly aged condition, where $f_{A}$ is the aging scale factor as derived in Eq. 1. The oxygenated products predicted by the explicit gas kinetic model are lumped as a function of vapor pressure (8 groups: $10^{-8}, 10^{-6}, 10^{-5}, 10^{-4}, 10^{-3}, 10^{-2}, 10^{-1}$, and $1 \mathrm{mmHg}$ ) and aerosol phase reactivity (6 groups), i.e., very fast (VF: tricarbonyls and $\alpha$-hydroxybicarbonyls), fast (F: 2 epoxides or aldehydes,), medium (M: 1 epoxide or aldehyde), slow (S: ketones), partitioning only (P), and multialcohol (MA). MGLY (methylglyoxal) and GLY (glyoxal) were lumped separately due to the relatively high reactivity. 


\section{Section S8. Impacts of aerosol acidity and humidity on ethylbenzene SOA yields or}

propylbenzene SOA yields
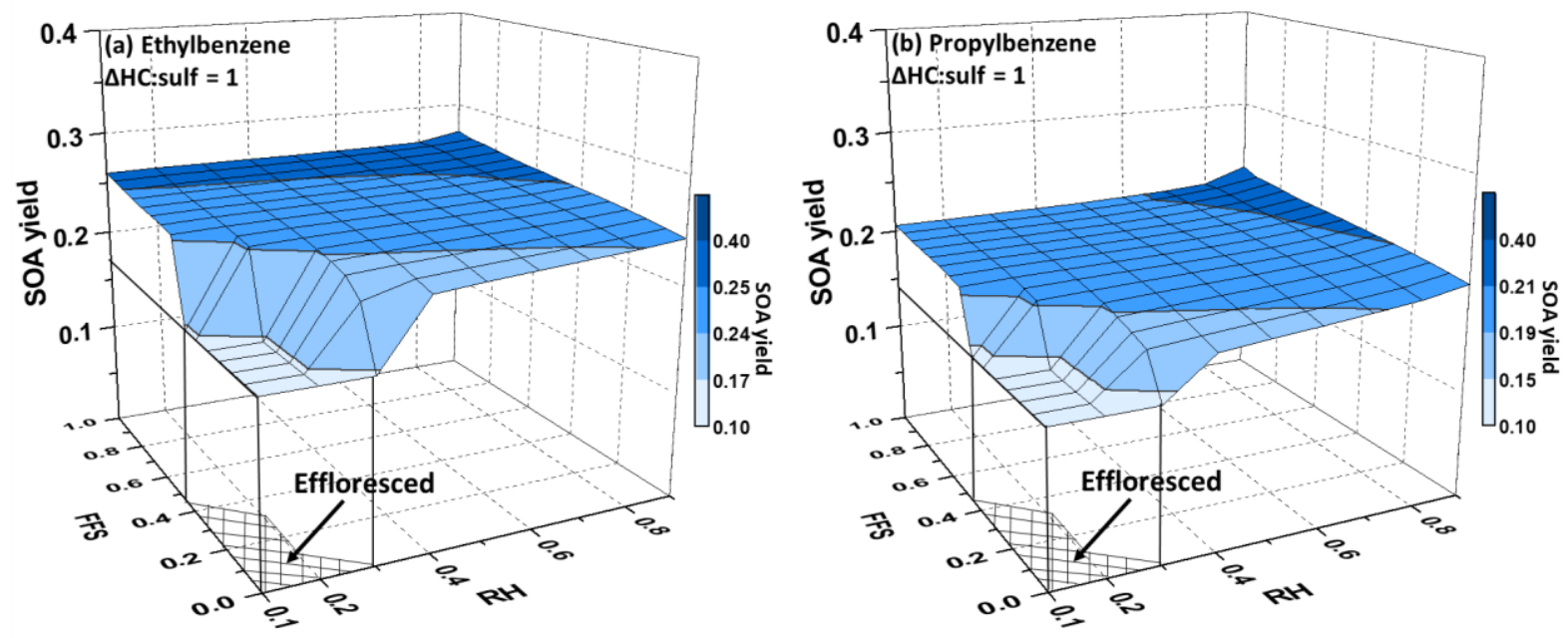

Figure S6: Simulated (a) ethylbenzene and (b) n-propylbenzene SOA yields $\left(\mathrm{Y}_{\mathrm{SOA}}=\right.$ $\Delta \mathrm{OM} / \Delta \mathrm{HC}$ at the end of the simulation, where $\Delta \mathrm{OM}$ is formed organic matter and $\Delta \mathrm{HC}$ is consumed HC) as a function of relative humidity (RH: $0.1 \sim 0.9$ ) and fractional free sulfate (FFS: $0 \sim 1)$, where FFS $=\left(\left[\mathrm{SO}_{4}{ }^{2-}\right]-0.5\left[\mathrm{NH}_{4}{ }^{+}\right]\right) /\left[\mathrm{SO}_{4}{ }^{2-}\right]$ and is another numerical indicator that used to estimate aerosol acidity $\left(\left[\mathrm{H}^{+}\right]\right)$in inorganic thermodynamic model. The RH and FFS are fixed during the simulations. The gas-phase simulations are based on the experimental condition of 06/14/2018 (Exp. Tol9 in Table 1) (initial HC concentration $=4.3$ and $7.4 \mathrm{ppb}$ for ethylbenzene and propylbenzene, respectively, $\mathrm{HC} / \mathrm{NO}_{x}=2$, pre-existing $\mathrm{OM}\left(\mathrm{OM}_{0}\right)$ mass concentration $=2 \mu \mathrm{g} / \mathrm{m}^{3}$, sulfate mass concentration $=20 \mu \mathrm{g} / \mathrm{m}^{3}$, and the mass ratio of the consumed $\mathrm{HC}$ to sulfate $(\Delta \mathrm{HC}$ :sulf) for ethylbenzene and propylbenzene $=1)$. 
Section S9. Simulation of SOA mass against chamber data obtained under various $\mathrm{NO}_{\mathrm{x}}$ levels, aerosol acidity, and humidity (dry and wet inorganic seed aerosol)
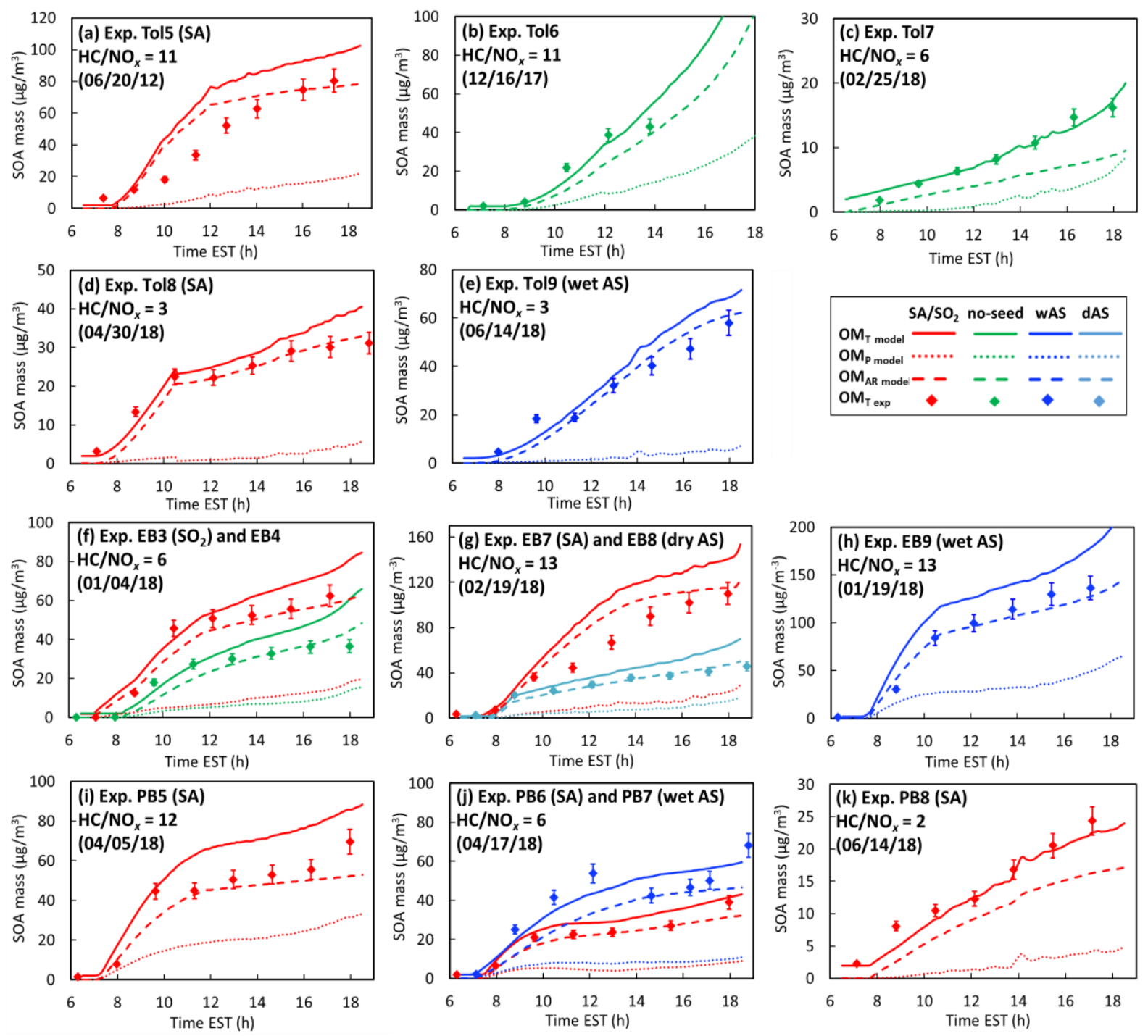

Figure S7: Time profiles of measured and modeled SOA mass concentrations for toluene (Tol: a-e), ethylbenzene (EB: f-h), and n-propylbenzene (PB: i-k) SOA under various $\mathrm{NO}_{x}$ levels in the presence/absence of inorganic seeded aerosol. The red, green, and blue colors indicate experiments with sulfuric acid seed, without inorganic seed, and with ammonium sulfate seed, respectively. SA denotes the direct-SA injection experiment. "wet" or "dry" in the figure denotes the physical state of the inorganic seed. Solid, dashed, and dotted lines denote total $\mathrm{OM}\left(\mathrm{OM}_{\mathrm{T}}\right)$, the $\mathrm{OM}$ from partitioning only $\left(\mathrm{OM}_{\mathrm{P}}\right)$, and the $\mathrm{OM}$ from the aerosol-phase reactions $\left(\mathrm{OM}_{\mathrm{AR}}\right)$, respectively. The uncertainty associated with experimentally measured $\mathrm{OM}$ is $9 \%$, which is estimated from the uncertainties of measured OC and correction of particle wall loss. The experimental conditions are available in Table 1 in the manuscript. 
Section S10. Uncertainties in UNIPAR predicted SOA mass for major model parameters

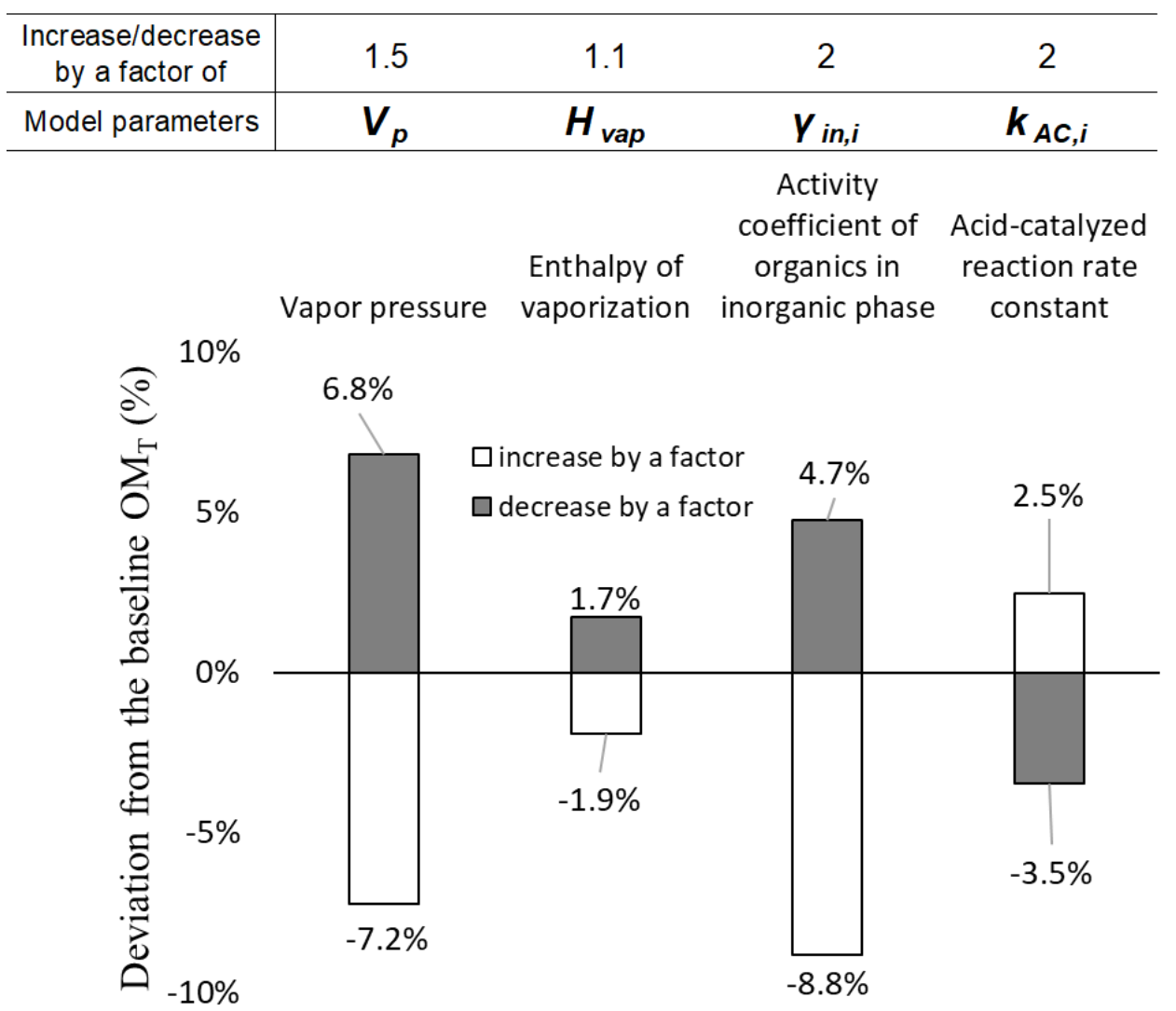

Figure S8: Prediction of model uncertainty (simulated SOA mass deviated from the reference SOA mass) due to the variation of major model parameters. The simulations employ the experiment performed on 06/14/2018 (Exp. Tol9 in Table 1 in the manuscript). The estimated errors associated with vapor pressure $\left(V_{p}\right)$, enthalpy of vaporization $\left(H_{v a p}\right)$, activity coefficients of the organics in the inorganic phase $\left(\gamma_{i n, i}\right)$ and oligomerization reaction rate constants in the inorganic phase $\left(k_{A C, i}\right)$ were predicted with increasing/decreasing the $V_{p}, H_{v a p}, \gamma_{i n, i}$, and $k_{A C, i}$ by factors of $1.5,1.1,2$, and 2 , respectively. 


\section{Reference}

Beardsley, R. L., and Jang, M.: Simulating the SOA formation of isoprene from partitioning and aerosol phase reactions in the presence of inorganics, Atmospheric Chemistry and Physics, 16, 5993-6009, 10.5194/acp-16-5993-2016, 2016.

Clegg, S. L., and Seinfeld, J. H.: Thermodynamic models of aqueous solutions containing inorganic electrolytes and dicarboxylic acids at $298.15 \mathrm{~K}$. 2. Systems including dissociation equilibria, J Phys Chem A, 110, 5718-5734, 10.1021/jp056150j, 2006.

Im, Y., Jang, M., and Beardsley, R. L.: Simulation of aromatic SOA formation using the lumping model integrated with explicit gas-phase kinetic mechanisms and aerosol-phase reactions, Atmospheric Chemistry and Physics, 14, 4013-4027, 10.5194/acp-14-4013-2014, 2014.

Jang, M., Czoschke, N. M., Lee, S., and Kamens, R. M.: Heterogeneous atmospheric aerosol production by acid-catalyzed particle-phase reactions, Science, 298, 814-817, 10.1126/science.1075798, 2002.

Jang, M., Cao, G., and Paul, J.: Colorimetric particle acidity analysis of secondary organic aerosol coating on submicron acidic aerosols, Aerosol Science and Technology, 42, 409-420, 10.1080/02786820802154861, 2008.

Jang, M. S., and Kamens, R. M.: Characterization of secondary aerosol from the photooxidation of toluene in the presence of NOx and 1-propene, Environmental Science \& Technology, 35, 3626-3639, 10.1021/es010676+, 2001.

Li, J., Jang, M., and Beardsley, R. L.: Dialkylsulfate formation in sulfuric acid-seeded secondary organic aerosol produced using an outdoor chamber under natural sunlight, Environmental Chemistry, 13, 590-601, 2016.

Li, J. Y., and Jang, M.: Aerosol Acidity Measurement Using Colorimetry Coupled With a Reflectance UV-Visible Spectrometer, Aerosol Science and Technology, 46, 833-842, 10.1080/02786826.2012.669873, 2012.

Stein, S. E., and Brown, R. L.: Estimation of Normal Boiling Points from Group Contributions, J Chem Inf Comp Sci, 34, 581-587, Doi 10.1021/Ci00019a016, 1994.

Zhao, L. W., Li, P., and Yalkowsky, S. H.: Predicting the entropy of boiling for organic compounds, J Chem Inf Comp Sci, 39, 1112-1116, Doi 10.1021/Ci990054w, 1999.

Zuend, A., Marcolli, C., Booth, A. M., Lienhard, D. M., Soonsin, V., Krieger, U. K., Topping, D. O., McFiggans, G., Peter, T., and Seinfeld, J. H.: New and extended parameterization of the thermodynamic model AIOMFAC: calculation of activity coefficients for organic-inorganic mixtures containing carboxyl, hydroxyl, carbonyl, ether, ester, alkenyl, alkyl, and aromatic functional groups, Atmospheric Chemistry and Physics, 11, 9155-9206, 10.5194/acp-11-91552011, 2011. 